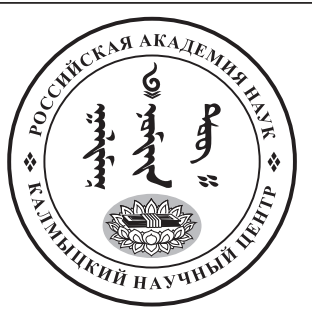

Published in the Russian Federation

Oriental Studies (Previous Name: Bulletin of the Kalmyk Institute

for Humanities of the Russian Academy of Sciences)

Has been issued as a journal since 2008

ISSN: 2619-0990; E-ISSN: 2619-1008

Vol. 13 , Is. 3 , pp. $560-571,2020$

DOI: $10.22162 / 2619-0990-2020-49-3-560-571$

Journal homepage: https://kigiran.elpub.ru

УДК 070: 654. 19 (470.57) «1950/1980»

DOI: 10.22162/2619-0990-2020-49-3-560-571

\title{
Эпигенез средств массовой информации в Башкирской АССР в 1950-1980-е гг.
}

\section{Зухра Рамилевна Сабирова ${ }^{1}$}

${ }^{1}$ Институт истории, языка и литературы Уфимского федерального исследовательского центра РАН (д. 71, пр. Октября, 450054 Уфа, Российская Федерация) кандидат исторических наук, старший научный сотрудник (iD) 0000-0003-1685-8901.E-mail: timerbulat2009@mail.ru

\author{
(C) КалмНЦ РАН, 2020 \\ (С) Сабирова 3. Р., 2020
}

Аннотация. Введение. В статье с привлечением документальных материалов и статистических сведений рассматривается развитие средств массовой информации в СССР в 1950-1980-е гг. на примере Башкирской республики. Цель исследования - показать на широком круге источников период 1950-1980-х гг. в развитии СМИ республики и дать ему характеристику. Для достижения цели были решены следующие задачи: проанализировано поэтапное развитие телевидения, радио и газет - каждого в отдельности; выявлены дифференциации в развитии СМИ; раскрыты общие черты эпигенеза средств массовой информации. Материалы и методы. Для исследования использованы архивные материалы на основе методов историзма, синтеза, альтернативности и многомерности в изучении проблемы, а также проблемно-хронологический принцип. Результаты. Показаны имевшиеся трудности в печати, на радио, телевидении и меры, которые принимались местными партийно-советскими органами по улучшению материально-технической и кадровой базы предприятий радио, телевидения и печатных органов, по ликвидации проблем «обратной связи с населением», участия населения в подготовке передач и публикаций. Автором уделено внимание политике советского государства по поддержке печатных органов республики, расширению сети телевизионного и радиовещания — в частности, выделению бюджетных средств на строительство новых релейных линий, ремонту действующих линий, улучшению сети сервисных организаций и др. Это способствовало выполнению важной задачи - полному покрытию сетью средств массовой информации территории республики, а значит - широкой пропаганде и агитации, быстрому информированию населения о переменах общегосударственного и республиканского уровня, созданию иллюзии демократичности этих источников информации. Показаны реформирование СМИ, введение новых программ в сетку вещания, изменения в политической цензуре. Активную помощь в 
подготовке передач и публикаций оказывало население республики: ученые, общественные и партийные деятели, писатели, поэты. Это способствовало наполняемости и распространяемости масс-медиа. Традиционной оставалась оглядка на политику партии, государства, цензура, поэтому участие жителей Башкирской республики в работе средств массовой информации носило несколько иллюзорный характер, хотя и содействовало успешному расширению содержания всех связей человека с республикой, городом или предприятием, на котором он работал. В процессе развития СМИ в указанные годы большое внимание уделялось обсуждению технических новинок в производстве, новым методам работы, обеспеченности населения социальными объектами и жильем, обмену опытом между республиками и БАССР. Поэтому в эти годы в республике увеличилось количество документальных фильмов, радиопередач «с полей» и «с производства», увеличился тираж газет, открылись новые фабрично-заводские и совхозные печатные органы. Bblводы. В ходе изучения данной темы автор пришел к выводу, что, несмотря на сложности развития средств массовой информации, наибольшей широты и охвата жизни общества они добились именно в это время.

Ключевые слова: средства массовой информации, телевидение, радио, печать, БАССР, активность общественности в 1950-1980-е гг.

Благодарность. Исследование проведено в рамках государственной субсидии проект «Духовная культура тюркских народов Южного Урала» (номер госрегистрации: AААA-A17-117040350082-3).

Для цитирования: Сабирова 3. Р. Эпигенез средств массовой информации в Башкирской ACCР в 1950-1980-е гг. // Oriental Studies. 2020. Т. 13. № 3. C. 560-571. DOI: 10.22162/26190990-2020-49-3-560-571

UDC 070: $654.19(470.57)$ «1950/1980»

DOI: $10.22162 / 2619-0990-2020-49-3-560-571$

\title{
Epigenesis of Mass Media in the Bashkir ASSR: 1950s - 1980s
}

\section{Zuhra R. Sabirova ${ }^{1}$}

${ }^{1}$ Institute of History, Language and Literature, Ufa Federal Research Centre of the RAS (71, Oktyabrya Ave., Ufa 540054, Russian Federation)-

Cand. Sc. (History), Senior Research Associate

iD 0000-0003-1685-8901. E-mail: timerbulat2009@mail.ru

(C) KalmSC RAS, 2020

(C) Sabirova Z. R., 2020

\begin{abstract}
Introduction. The article examines the development of Soviet mass media between the 1950s and 1980s through the example of the Bashkir Republic. Goals. The paper seeks to show the mentioned period was characterized by the most consistent and qualitative development of mass media. To facilitate this, the following objectives be tackled: analysis of the gradual development of television, radio and newspapers; identification of differences in the development of mass media; clarification of common features inherent thereto. Materials and Methods. The work analyzes archival materials, and employs methods of historicism, synthesis, alternative, and multidimensional approach to study the problem; the problem-chronological principle proved as instrumental. Results. The paper shows the then difficulties in radio, television and print media, and the measures taken by local party and Soviet authorities to improve the material, technical and personnel aspects, eliminate the problems of 'feedback from the population'; the latter's participation in the preparation of programs and publications. The article pays attention to the policy of the Soviet state aimed at supporting the republic's print media, expanding the network of television and radio broadcasting, in particular, allocation of budget funds for the construction of new relay lines, repair of existing ones, and improvement of the network of service organizations, etc. This resulted in that the whole territory
\end{abstract}


of the republic got covered with mass media networks. It also facilitated broader propaganda and agitation, faster distribution of information about changes at national and regional levels, creation of the illusion those media sources were essentially democratic. The work describes the reform of the media, introduction of new programs, and related changes in political censorship. Scientists, public and party figures, writers, poets - the population - took an active part in the preparation of programs and publications. This increased completeness and distribution levels of the media. However, during this period people still tended to keep an eye on the policy of the Party / state, and censorship of topics was as actual, which made the participation of Bashkir ASSR's residents in that work somewhat illusory, although it did successfully expand (and strengthen) all ties between an individual - and the republic, city, or factory he / she worked at. The mentioned years witnessed a high demand for discussions over technical innovations, new methods of work, development of social infrastructure and housing, exchange of experiences between the Bashkir ASSR and other Soviet republics. Therefore, in those years, the number of documentaries, radio programs 'from fields' and 'from workshops' - and readership circulation - significantly increased, new printing agencies were established both in urban and rural areas. Conclusions. The paper concludes that despite all travails and vicissitudes it is in the 1950s - 1980s that mass media achieved their maximum social comprehensiveness and breadth.

Keywords: mass media, television, radio, print, Bashkir ASSR, public activities in the 1950s - 1980s. Acknowlegdements. The reported study was funded by government subsidy — project name 'Turkic Peoples of the Southern Urals: Spiritual Culture' (state reg. no. AAAA-A17-117040350082-3).

For citation: Sabirova Z. R. Epigenesis of Mass Media in the Bashkir ASSR: 1950s - 1980s. Oriental Studies. 2020. Vol. 13(3): 560-571. (In Russ.). DOI: 10.22162/2619-0990-2020-49-3-560-571

\section{है}

\section{Введение}

Историография проблемы пока носит скудный характер. Общим вопросам посвящены работы Л. Н. Когана, Н. С. Симонова, В. В. Миркина [Коган 1966: 7-8; Симонов 2013; Миркин 2013: 200-207].

Региональные публикации по истории развития телевидения, радио и печати носят в основном научно-популярный характер [Нуриев 1964: 3-4]. Но есть среди них добротные труды, например, монографии Ф. Т. Кузбекова, К. К. Каримова, Т. И. Ахунзянова, Р. У. Кузыева, А. Утешева и Р. М. Янгирова [Кузбеков 2006; Каримов 2006; Янгиров 2001; Кузыев 1958; Утешев 1962].

Новейшая историография также уделила внимание истории развития средств массовой информации в статьях [Буравцов 2016; Сабирова 2019; Сабирова 2017]. Однако основная масса исследований носит фрагментарный или описательный характер, либо эмпирический и аналитический материал в них устарел. Особенно это наглядно при рассмотрении истории эпигенеза СМИ во второй половине XX в. в таком многонациональном регионе, как Башкирская АССР (далее - БАССР). Ибо период насыщен изменениями политического и социально-экономического характера. В связи с этим целью данного исследования является изучение динамики развития средств массовой информации в БАССР в 1950-1980-е гг.

\section{Материалы и методы}

Источниковую базу исследования составили архивные материалы непосредственно из фонда - Комитета по телевидению и радиовещанию Совмина БАССР и Управления издательств и полиграфии БАССР. Объемный и развернутый материал дают также отчеты служащих предприятий в партячейки и высшие партийные органы о работе радио, телевидения и печатных органов, о работе средств массовой информации по выполнению постановлений общегосударственного и республиканского уровня, о планировании и тематических раскладках готовящихся передач и материалов; постановления партийных органов по их работе, замечания и протоколы совещаний Совета министров БАССР. Вполне информативный материал дают и опубликованные источники, в частности периодика указанных лет (статьи на злободневные темы и о новаторском движении, письма в редакцию и т. д.). 
В процессе исследования использованы методы историзма, синтеза, альтернативности и многомерности в изучении проблемы, а также проблемно-хронологический принцип.

Динамика развития средств массовой информации в БАССР в 1950-1980-е гг.

Масштабные и глубокие культурные преобразования, произошедшие в Башкирии во второй половине XX в., дали развитие различным национальным культурным переменам. В их основе лежали принципы коллективизма и подъем жизненного уровня населения [Riasanovsky 2000].

B послевоенные годы совершенствование и развитие технических средств распространения культуры - телевидения, радио, печати и книгоиздательства - приобретает еще большее значение. Цель совершенствования заключалась в постепенном подъеме до уровня города духовной жизни тружеников села, сближения и взаимообогащения культуры «социалистических» наций. Одним из главных средств формирования гармонично развитых граждан общества в послевоенный период становится эстетическое воспитание. Эстетические взгляды человека становятся неотъемлемой составной частью его мировоззрения, а также определяющим показателем духовного развития личности.

Телевидение в БАССР в 1950-1980-е гг.

Исходя из решений Третьей сессии Верховного Совета РСФСР (пятого созыва) в 1960 г., Пятая сессия (пятого созыва) Верховного Совета Башкирской республики в декабре 1960 г. постановила в целях развития материальной базы сельских учреждений «...разработать на 1961-1965 г. план строительства учреждений культуры в сельской местности с привлечением средств колхозов, потребительской кооперации и профсоюзных организаций, а также трудового участия населения» [Заседание ВС БАССР 1960: 162].

Государственные органы республики обязаны были приложить все силы, чтобы закончить до конца семилетки сплошную радиофикацию всех сел в Башкирии, иметь стационарную киноустановку в каждом селе, насчитывающем более 50 дворов, завершить охват библиотечным обслуживанием каждого населенного пункта в республике [Заседание ВС БАССР 1960:
159-162]. Этот план был успешно выполнен. К началу 1965 г. в селах Башкирии, где проживало около двух миллионов человек, работало 3114 клубов и Домов культуры, 1332 библиотеки, 2343 киноустановки, 95 книжных магазинов. В домах колхозников, рабочих совхозов и сельской интеллигенции было 135 тысяч радиоприемников, 286 тысяч радиоточек, более 10 тысяч телевизоров [Нуриев 1964: 31].

В 1962 г. в селах Башкирии насчитывалось 1844 киноустановки. В 1965 г. села обслуживали 2107 киноустановок, в том числе 1664 стационарных [Народное хозяйство 1964: 262].

В завершающем году семилетки на каждого жителя республики приходилось в среднем по 17 посещений кино в год [Янгиров 1972: 169].

Развитие кинотехники позволило осуществить демонстрацию фильмов, дублированных на башкирский язык. К началу 1965 г. в республике уже демонстрировалось 162 художественных фильма на башкирском языке, в том числе 54 дублированных и 108 субтитрированных [Янгиров 1972: 174]. Это означало, что каждый четвертый фильм, выходивший на экраны республики, имел копии на башкирском языке.

С 1966 г., после строительства ретрансляционных вышек от центра до Уфы началась трансляция каналов передачи Центрального телевидения. Вначале транслировался только первый канал. С 1967 г. телецентр начал транслировать вторую телевизионную программу из Уфы. Передачи второго канала шли вперемешку с местными передачами. УКВ приставка позволяла смотреть передачи на выбранном зрителем языке.

В годы семилетки в Башкирии утвердился новый вид самодеятельного художественного творчества — кинолюбительство. Участники самодеятельных киностудий средствами кино отражают повседневную жизнь своих трудовых коллективов, знакомят тысячи зрителей с передовиками производства, рассказывают об их отдыхе, творческих устремлениях.

В Октябрьском в 1957 г. кинолюбители организовали выпуск киножурнала «Нефтяной край», который рассказывал о трудовых буднях, учебе и отдыхе нефтяников одного из крупнейших центров Второго Баку. За 
полтора года коллектив самодеятельной киностудии подготовил 6 выпусков киножурнала [Ғабизуллин 1957: 2; Курбанов 1959: 2; Новиков 1962: 2; Маннанов 1971: 1; Закрепляют успехи 1976: 1].

Фильм «Алмазное бурение», снятый группой научных работников - В. Колокольцевым, Ю. Слеповым, М. Юнусовым, членами любительской киностудии Уфимского нефтяного научно-исследовательского института, демонстрировался летом 1961 г. в Баку на Всесоюзном совещании работников нефтяной промышленности и получил высокую оценку специалистов-нефтяников. В тот же год на II Всесоюзном фестивале любительских фильмов его авторы были удостоены III премии ВЦСПС за удачную пропаганду технического прогресса и внедрение современных технических методов в промышленность [Новиков 1962: 2; Oukaderova 2017].

С 1975 г. телевидение Башкортостана стало цветным. Были построены радиорелейные линии Казань - Уфа, Бураево - Караидель, Салават - Учалы. Это позволило охватить телевидением 85 \% населения республики [НА РБ. Ф. П-933. Оп. 9. Д. 2109. Л. 261-262].

Отметим, что советский период, особенно период семилетки, отмечен непрерывным совершенствованием материальной базы культуры, планомерным возрастанием государственных ассигнований на культурное строительство, результатом чего становится стирание существенных различий между городом и деревней, повышение общеобразовательного уровня населения, подготовки специалистов, развития культуры.

\section{Периодическая печать и книгоизда- тельство}

Продолженная советской печатью традиция быть главным источником достоверной и востребованной информации для населения в целом себя оправдала и тогда, когда к средствам массовой информации добавились радио и телевидение, способствовала распространению агрономических, политических, культурно-бытовых и других знаний среди населения.

Помимо газет, журналов, альманахов, листовок и т. д., большую роль играли книги для массового читателя, выпуску которых способствовало созданное в октябре
1922 г. в Уфе и ставшее главным издательством для БАССР во второй половине XX в. объединение «Башкнига». Естественно, что определенную долю в них занимала политическая литература - Устав РКП(б), учебник политграмоты и др. [Куватов 1969: 14], труды классиков марксизма-ленинизма.

С 23 декабря 1940 г. и позже оно входило в ведение Управления издательств и полиграфии. На него возлагалось руководство плановой, организационной, финансовой, административно-пропагандистской деятельностью предприятий [НА РБ. Ф. Р-1927. Оп. 1. Д. 1. Л. 187].

Важной вехой в развитии книжного и газетного дела в Башкортостане, как и в стране, стало выделение в 1953 г. Главного управления по охране военных и государственных тайн в печати (Главлит) из системы Министерства внутренних дел СССР в самостоятельное управление в подчинении Совета министров СССР и на местах - Coветов министров союзных и автономных республик, исполкомов краевых и областных Советов депутатов трудящихся. За неимением свободных работников обязанности по выполнению работы Главлита на местах возлагались на ответственных работников аппаратов райисполкомов или райкомов КПСС, утвержденных в вышестоящих инстанциях с надбавкой к зарплате в 300500 рублей в месяц [НА РБ. Ф. 933. Оп. 9. Д. 1272. Л. 7].

Вторым важным шагом была постановка Советом министров РСФСР перед Министерством просвещения Башкирской ACCP, Башполиграфиздатом и Башкирским книжным издательством задачи обеспечить в 1953-1954 гг. издание учебно-наглядных пособий по родному языку и родной литературе для башкирских школ, находившихся в Башкирской АССР и вне автономной республики; создать при Министерстве просвещения Башкирской АССР комиссию по рассмотрению учебно-наглядных пособий по башкирскому языку и башкирской литературе [НА РБ. Ф. 933. Оп. 9. Д. 1241. Л. 88, 90]. В 1950 г. в БАССР по подписке газеты распространялись в количестве 407 тыс. экз. против 310 тыс. в 1940 г. В сельской местности в том же 1940 г. на каждые 4-5 домов приходилось по одному экземпляру, в то время как в 1953 г. каждый колхозный дом получал 1-2 экземпляра [НА РБ. 
Ф. 804. Архив Госплана при Совете Министров. Справка о развитии хозяйственных отраслей БАССР в 1940-1953 гг.].

Резко улучшается и качество выпускаемой продукции. Причиной тому улучшение материально-технической базы издательств и типографий, расширение сети книжных магазинов, рост распространяемости выходящей литературы. Совершенствование полиграфической базы издательского дела [НА РБ. Ф. 122. Оп. 20. Д. 328. Л. 193] способствовало и качественным изменениям многотиражных ведомственных печатных газет [НА РБ. Ф. 122. Оп. 20. Д. 328. Л. 304].

На страницах газет укрепилась рубрика «Партийная жизнь». Большинство материала, как и в довоенный период, было посвящено работе, воспитанию и образованию молодых коммунистов. Широкое освещение на ее страницах получили темы о вовлечении в общественное производство женщин-домохозяек, о роли мастера на производстве, о необходимости изжить простои оборудования, о повышении культуры земледелия, увеличении продуктивности скота, об укреплении экономики колхозов, развитии растениеводства; после военного периода и вплоть до конца 1980-х гг. много внимания уделялось обсуждению на страницах печатных органов социалистических соревнований.

Другой темой газетных публикаций был поиск «собственных ресурсов», например, использование в животноводстве забытого на какое-то время башкирского клевера. Кроме этого, на страницах периодической печати делились опытом с соседними областями и даже республиками, подробно обсуждалась тема развития животноводческих ферм и МТС [Мусалитин 1980: 2].

Интересный материал с 1950-х гг. дают циклы о шефской помощи предприятий сельским районам, большей частью по благоустройству села. Привлекает внимание и обсуждение, а также цифровые данные о повышении денежной доходности на одного трудоспособного в сельхозартелях [Ахунзянов 1970: 114, 119, 120, 123, 125].

Большую популярность приобретает в конце 1950-х и в 1960-е гг. газета «Ленинсы» («Ленинец»), при которой работало молодежное литературное объединение. Издание уделяло много внимания работе с письмами и авторским активом. В 1960-е гг. в нем публиковались Б. Рафиков, Т. Сагитов, Г. Шафиков, Э. Нуриджанов, Л. Нечаева, А. Зиновьев, М. Гафуров и др., ставшие в будущем известными башкирскими писателями, поэтами, журналистами, учеными, общественными деятелями [Кузбеков 2006: 305].

В 1968 г. на свет появляется журнал «Башкортостан кызыы» («Дочь Башкортостана»), а в 1969 г. начинает выходить газета «Вечерняя Уфа». С учетом потребностей сельского хозяйства был налажен выпуск журнала «Сельское хозяйство Башкирии», выходившего 1 раз в месяц тиражом в 10 тыс. экз.

В 1960-1970-е гг. темой, не сходившей со страниц СМИ, была также проблема увеличения зернового производства — эффективные меры повышения урожайности, внедрение новых, высокопродуктивных сортов [Рамазанов 1976: 4].

В 1980-е гг. внимание читателей корреспонденты акцентировали и на экономической теме (получение экономического образования, размышления на тему эффективности предприятий, хозрасчетные формы хозяйствования на селе, ввод самоуправления в бригадных и звеньевых уровнях и т. д.) [Гареев 1979: 2; Камалов 1979: 1]. Все еще важной оставалась рубрика «Уроки новаторства». Проблемные выступления основывались в своем большинстве на письмах читателей. Так на страницах печати появляются публикации на тему наболевших социальных проблем села [Рамазанов 1976: 4; Юғары баһа 1977: 3; Утәгәнов 1978: 4; Комиссаров 1980: 4].

Информация с развитием рабселькоровского движения стала полнее, их посты в 1968 г. исчислялись 1630 точками. Их материалы становились предметом обсуждения на бюро райкомов партии. К середине 1970-х гг. численность рабселькоров достигла 30 тысяч человек [Ахунзянов 1976: 54]. Повсеместно стали открываться школы рабселькоров.

Однако все газеты являлись органами соответствующих партийных комитетов, что вело к невозможности открыто обсуждать принципиальные вопросы и вскрывать серьезные недостатки. Все это усугублялось бесконечными одергиваниями со стороны парткомитетов. Но стремление редакторов и корреспондентов охватить все стороны 
жизни общества, доступная цена и контроль распространения среди различных социальных слоев обеспечивали газетам стабильный интерес и рост тиража. Застойные явления в политике и культуре нашего государства ранее всего проявились именно в работе средств массовой информации. Критические материалы стали выходить «с оглядкой» на партию.

Отрицательно сказалась в 1963 г. и попытка центра ликвидировать национальные газеты и превратить их в переводные версии центральных изданий. Первые действия, по словам Расиха Ханнанова, главного редактора «Кызыл Тан», были предприняты в отношении его газеты и «Совет Башкортостаны». Это вызвало волну протеста журналистов башкирских и татарских изданий, деятелей культуры, литературы, учителей, стихийно собравшихся в один день в здании Союза писателей, а затем прошедших к зданию обкома БАССР. Как отметил Р. Ханнанов, «очевидно, протест в Москве был принят к сведению. Возможно, и в других республиках были аналогичные акции, и это сыграло роль, но факт, что в ЦК в итоге пошли на компромисс. Приняли сначала решение печатать как дубляж главной русскоязычной газеты три первые страницы республиканских национальных газет, а под оригинальные материалы, художественные произведения на национальных языках выделить последнюю полосу. Однако после критики и такого решения оставили самостоятельные национальные газеты, как есть, и просто сократили бюджет их финансирования на 10 \%» [Писатель Расих Ханнанов 2006].

Как бы то ни было, в этот период выпускалось только 8 изданий на башкирском языке: республиканские «Совет Башкортостаны», «Башкортостан пионеры», «һәнәк» ('Вилы'), «Башкортостан кызы» ('Дочь Башкортостана'), «Пионер», «Башкортостан укытыусыһы» ('Учитель Башкортостана'), «Агидель» и бурзянская «Тан». При этом дубляжных вариантов - 23 [Тимербулатов 2020: 43].

Средства массовой информации прошли большой путь качественного развития в $\mathrm{XX}$ в. Наибольшей широты и охвата жизни общества они добились именно во второй его половине. Источником их функционирования была в основном информация мест- ного характера, которая рассказывала о взаимосвязи человека с республикой, городом или предприятием, на котором он работал. Это позволяло говорить о насущных проблемах социально-экономического, политического, культурного, демографического развития региона и страны в целом, включить в обсуждение их самые различные слои населения как в возрастном и социальном смысле, так и гендерном, и национальном [The Socialist Sixties 2013].

\section{Радио и радиофикация}

Радио, в свою очередь, как мощное идеологическое оружие, пришедшее в республику еще в 1919 г., в течение всего периода своего существования решало и решает часть общеобразовательных и социальных проблем, задачи пропаганды и агитационно-массовой работы, повышения грамотности и культуры населения, полезного досугового времяпровождения [Wolfe 2005; Zerneva 2001: 14710-14715].

Для популяризации радиодела, а также для информирования населения о новинках радиоизобретательства и для обучения его самостоятельному обращению с радиоаппаратурой, в 1950-е гг. стали выходить различные журналы и газеты, посвященные радио, радиолюбительству, радиоспорту и пр.: «Радио всем», «Радиофронт», «Радиолюбитель». При станциях юных техников подростков обучали принципам работы радиосвязи, а в ассортимент игрушек были включены самосборные радиоточки.

Радиосвязь БАССР с Баку, Ташкентом, Алма-Атой, Владивостоком, Куйбышевом, Москвой, Оренбургом, Хабаровском берет свое начало в 1941 г., когда несколько коротковолновых радиопередатчиков ДРК150, эвакуированных из Москвы для связи с отдельными городами СССР в диапазонах волн 25-50 и 19-31 м, установили в здании PB-37 в Уфе, а в д. Дмитриевка Уфимского района построили приемный пункт радиостанции РВ-37. Республика могла делиться своими новостями с самыми разными уголками государства, а наши слушатели быть в курсе их жизни. Этот опыт лег в основу радиожурнала «Между Волгой и Уралом», который впервые вышел в эфир в 1958 г. Нашу республику услышали жители Татарской, Чувашской, Удмуртской, Мордовской и Марийской АССР. 
В послевоенные годы уделялось большое внимание радиофикации сельской местности, увеличению мощностей радиоузлов в районах республики и в Уфе. Планирование строительства радиотрансляционных линий основывалось уже на полной радиофикации объектов машинотракторных станций и населенных пунктов при них [НА РБ. Ф. Р-933. Оп. 9. Д. 1276. Л. 160].

Техническая работа радиовещания в БАССР развивалась в соответствии с проектом генеральной реконструкции радиосети, которым предусматривалось новое узлообразование сооружений радиофикации с учетом перспективы развития населенных пунктов. Этому способствовала Пятая сессия (пятого созыва) Верховного Совета Башкирской республики в декабре 1960 г., которая постановила в целях развития материальной базы сельских учреждений «...разработать на 1961-1965 годы план строительства учреждений культуры в сельской местности с привлечением средств колхозов, потребительской кооперации и профсоюзных организации, а также трудового участия населения» [Заседание ВС БАССР 1961: 162].

Этот план был успешно выполнен. К 1964 г. в республике было построено 320 радиоузлов, радиофицировано 1080 населенных пунктов, число радиоприемных и телевизионных установок на селе увеличилось на 159 тысяч и составило 20 установок на 100 человек [НА РБ. Ф. П-933. Оп. 9. Д. 1828. Л. 229-233].

Новая генеральная схема радиофикации 1973 г. предусматривала развитие станционных и линейных сооружений в соответствии с планом застройки и интенсивную модернизацию устаревшего оборудования. Кроме того, как признавали сами работники радио, «У радио появился серьезный конкурент телевидение. Поэтому, чтобы выдержать конкуренцию, надо искать, создавать интереснейшие передачи на очень высоком идейно-художественном уровне», такие как, например, передача «,Именем закона и совести“"»; «уделять больше внимания экономической реформе и хозяйственному расчету» [НА РБ. Ф. П-9860. Оп. 1. Д. 18. Л. 28].

В передачах чаще стали обсуждаться проблемы экономии сырья, механизации и автоматизации трудоемких процессов производства, увеличения продуктов сельского хозяйства и снижения их себестоимости.
Появились новые рубрики - «трибуна рабочего» и «трибуна труженика села» [HА РБ. Ф. П-9860. Оп. 1. Д. 19. Л. 2-5, 105], «Голоса друзей» (стихи поэтов других регионов), «На экране сельские таланты».

Работе редакции радио «мешали нехватка гонораров, частое перемещение кадров и их текучесть», одной из причин текучести была необеспеченность работников радио квартирами. На качестве подготовки передач сказывался «частый отрыв работников на хозяйственные нагрузки (мясокомбинат, заготовку овощей, картофеля и т. д.), ... по заданию исполкома Ленинского райсовета машины радио отвлекали на другие нужды» [НА РБ. Ф. П-9860. ОП. 1. Д. 19. Л. 103-105].

В 1960-1970-е гг. радио достигло успеха в культурно-просветительной работе, выросло тематическое разнообразие радиопередач. Однако определяющее воздействие на работу радио оказывали подготовка и празднование знаменательных дат, партийные и государственные органы продолжали нацеливать редакторов и корреспондентов на усиление идейного воспитания населения, пропаганду марксизма-ленинизма, для чего использовались не только разовые передачи, но и подготовка циклов лекций, выступлений лекторов народных университетов, беседы с передовиками производства и известными личностями [История Уфы 1981: 562-563].

Несмотря на некоторое смягчение политической цензуры в СССР после ХХ съезда КПСС, она не была полностью отменена. Поэтому работа радио БАССР была подчинена принятому в 1962 г. новому Положению о передачах Всесоюзного радио, в котором предусматривалось конкретное и точное определение содержания и жанра планируемых передач, организация сезонных (осенне-зимней и весенне-летней) сеток вещания; а также принятому в марте 1964 г. постановлению Совмина РСФСР об обязательном наличии радиотрансляционной сети во всех строящихся жилых домах [Симонов 2013: 83]. Следует отметить, что радиовещание в те годы состояло преимущественно из ретрансляции передач центральной программы.

Конечно, внутри БАССР районное радиовещание, транслировавшее передачи на репродукторы и радиоприемники, работало часто на общественных началах, в виде «ра- 
диогазеты». Но они все же прочно занимали свое место в культурной и общественно-политической жизни республики, и в 1960-е гг. таких радиогазет было уже более 400 [Сабирова 2017: 71-78].

В составе сотрудников радиогазет редакционная коллегия, дикторы, корреспонденты. Репродукторы размещались не только в домах колхозников, но и на поле и фермах, в клубах и школах, поликлиниках и больницах. Из них повседневно звучал голос диктора, на родном языке рассказывавшего о новостях района, колхоза, бригады. В подготовку передач вкладывали свое свободное время и опыт рабочие и колхозники, работники культуры и искусства, медицинские работники. Были среди них и сотрудники правоохранительных органов. Привлечение широких масс населения к работе радио, пусть даже на общественных началах, создавало эффект ответной реакции народа в ответ на директивы и пленумы партии, новости страны и мира.

\section{Выводы}

В целом в работе республиканских средств массовой информации именно в эти годы произошел качественный рост. Но, несмотря на определенные успехи, до середины 1980-х гг., например, периодическая печать республики страдала однобоким подходом в освещении некоторых значимых вопросов. Не изжила себя привычка «рапортовать» о съездах партии, их подготовке и проведении. Ярко прослеживается в материалах показное и формальное. Несоответствие управленческого аппарата изменившимся условиям, идеологизация жизни, расхождение между словом и делом произвели пагубное влияние и на развитие печати, привело к одностороннему обмену информацией.

Печать призвана отражать природу, внутреннее содержание, интересы и личностные установки народа, проживающего здесь. Это дает ему возможность развивать свою культуру, сохранять язык, формировать чувство духовного единства. Однако в советский период из-за политики «сближения наций» многие стали постепенно утрачивать признаки идентичности. Государственно-идеологическая автаркия, контролировавшая общественную, групповую и личную жизнь человека, сделала прессу компонентом этого процесса. Считалось, что «получили развитие многонациональные по форме культуры в условиях единой государственности, на основе взаимообогащения» [Янгиров 1972: 168].

Сейчас информационное пространство довольно широко, разнообразно, увеличивается за счет электронных изданий. На фоне общероссийского медиапространства здесь также действуют как государственные издания, газеты и журналы, так и ведомственные, профильные, корпоративные, региональные и т. Д. Но отметим, что их современное развитие уходит корнями в постсоветскую и советскую культуру по широте охвата проблематики, принципам привлечения информационных источников.

Технические возможности радио оказались безграничны. Радиосвязь дала впоследствии начало таким современным научно-техническим направлениям, как радиоастрономия, радиометрология, радионавигация, радиолокация и радиоразведка, радиопротиводействие, скачок в развитии которых пришелся на 1950-1970-е гг. Радио было повсеместно популярно и информативно. Именно в эти годы и в СССР, и в БАССР оно получило широкую аудиторию. В отличие от предыдущего периода, когда оно было скорее оповестительным средством для населения, в послевоенные годы и до середины 1980-х гг. радио уже стало таким же незаменимым спутником жизни населения, как и книга, газета, журналы, телевидение. Для многонациональной республики радио выполняло часть задач общеобразовательного и социального характера, осуществляло воспитательные функции среди различных категорий населения, оказывало влияние на уровень грамотности и культуры людей, являлось широковещательным средством не только массовой информации, но также агитации и пропаганды.

Касательно развития телевидения, телевизионного и кинотворчества во второй половине XX в. можно отметить, что внедрение в повседневную культуру общества телевидения было подхвачено населением с энтузиазмом. Расширение информационного пространства, ознакомление с техническими новинками и в то же время возможность глубокого творческого самовыражения положило начало целому культурному течению, кинолюбительству, которое 
неожиданно для государственных органов быстро и стихийно стало наращивать темпы. Но и здесь правительство быстро взяло под контроль инициативу масс.

Важным итогом эпигенеза средств массовой информации в 1950-1980-е гг. в БАССР как для телевидения, так и для радио и печатных органов стало укрепление систематичности в работе, что мы наблюдали в последующие годы и которую мы на-

\section{Источники}

Ғабизуллин 1957 - Ғабизуллин Р. Техник прогресс нигезुендә (= На основе технического прогресса) // Нефтяник Башкирии. 1957. № 375 (1184). C. 2.

Гареев 1979 - Гареев Д. На поля - лучшие сорта // Советская Башкирия. 1979. № 270 (1919). 25 ноября. С. 2.

Закрепляют успехи 1976 - Закрепляют успехи // Советская Башкирия. 1976. № 2 (18016). 4 января. С. 1.

Заседание ВС БАССР 1960 - Заседание Верховного Совета Башкирской АССР пятого созыва (пятая сессия), 15-16 декабря 1960 года. Стенографический отчет. Уфа, 1961. C. 162 .

Камалов 1979 - Камалов А. Скажется на урожайности // Советская Башкирия. 1979. № 84 (19011). 15 апреля. С. 1.

Комиссаров 1980 - Комисаров Ф. Халык малын кем көтә (= Кто пасет народный скот) // Совет Башкортостаны (= Советская Башкирия). 1980. № 184 (17681). 12 августа. С. 4.

Курбанов 1959 - Курбанов С. Двухдневный экономический семинар // Советская Башкирия. 1959. № 74 (11154). 29 марта. С. 2.

Маннанов 1971 - Маннанов $A$. Слово строи-

\section{Sources}

National Archive of the Republic of Bashkortostan.

Appreciation and specific targets. Sovetskaya Bashkiria. 1977, June 10. No. 135 (16728). P. 3. (In Bash.)

Consolidating success. Sovetskaya Bashkiria. 1976, January 4. No. 2 (18016). P. 1. (In Russ.)

Gabizullin R. On the basis of technical progress. Neftyanik Bashkirii. 1957. No. 375 (1184). P. 2 (In Bash.)

Gareev D. Best cultivars - onto the fields. Sovetskaya Bashkiria. 1979, November 25. No. 270 (1919). P. 2. (In Russ.)

Kamalov A. Supposed to positively impact crop yields. Sovetskaya Bashkiria. 1979, April 15. блюдаем сейчас. Кроме того, произошла все же постепенная «демократизация цензуры». Повысилась роль радио, телевидения, газет и журналов в жизни общества, их массовость в сравнении с предыдущими историческими периодами. Появились новые темы и формы в их профессиональной деятельности, а также новые формы организационно-массовой работы. Обновился характер социальной информации.

телей Арлана // Советская Башкирия. 1971. № 108 (16595). 7 мая. С. 1.

Мусалитин 1980 - Мусалитин Б. Әйткән һүз аткан ук (= Слово - выпущенная стрела) // Совет Башкортостаны (= Советская Башкирии). 1980. 28 мая. С. 2.

НА РБ - Национальный архив Республики Башкортостан.

Народное хозяйство 1964 - Народное хозяйство и культурное строительство Башкирской АССР. Уфа: Статистика, 1964. 292 с.

Новиков 1962 - Новиков М. В труде мужают // Советская Башкирия. 1962. № 87 (11154). 12 апреля. С. 2.

Рамаз̧анов 1976 - Рамаз̧анов F. Файз̧алы һөйләшеү (= Разговор с пользой) // Совет Башкортостаны (= Советская Башкирия). 1976. № 132 (16419). 6 июня. С. 4.

Утәгәнов 1978 - Утәгәнов М. Файз̧алы тармак (= Полезная отрасль) // Совет Башкортостаны (= Советская Башкирия). 1978. № 255 (17152). 3 ноября. С. 4.

Юғары баһа 1977 - Юғары баһа һәм анык бурыстар (= Высокая оценка и конкретные задачи) // Совет Башкортостаны (Советская Башкирия). 1977. № 135 (16728). 10 июня. C. 3 .

No. 84 (19011). P. 1. (In Russ.)

Komarov V. N. (ed.) Bashkir ASSR: Public Economy and Culture Building. Ufa: Statistika, 1964. 292 p. (In Russ.)

Komisarov F. Who herds public cattle. Sovetskaya Bashkiria. 1980, August 12. No. 184 (17681). P. 4. (In Bash.)

Kurbanov S. Two-day economic seminar. Sovetskaya Bashkiria. 1959, March 29. No. 74 (11154). P. 2. (In Russ.)

Mannanov A. Word of those who build Arlan. Sovetskaya Bashkiria. 1971, May 7. No. 108 (16595). P. 1. (In Russ.)

Meeting of the $5^{\text {th }}$ Supreme Soviet of the Bashkir ASSR (Session Five): 1960, December 
15-16. Verbatim Report. Ufa, 1961. P. 162. (In Russ.)

Musalitin B. Word as a launched arrow. Sovetskaya Bashkiria. 1980, May 28. P. 2. (In Bash.)

Novikov M. Gaining strength in work. Sovetskaya Bashkiria. 1962, April 12. No. 87 (11154). P. 2.

\section{Литература}

Ахунзянов 1976 - Ахунзянов Т. И. Идейно-политическая направленность печати. М.: Политиздат, 1976. 62 с.

Ахунзянов 1970 - Ахунзянов Т. И. Печать Советской Башкирии. Кн. 2. Уфа: Башкнигоиздат, 1970.364 c.

Буравцов 2016 - Буравиов В. История средств связи в Уфе // Бельские просторы. № 4 (209), апрель, 2016. С. 130-133.

История Уфы 1981 - История Уфы. Краткий очерк / 2-е изд., исправл. и доп., под ред.: Ганеева Р. Г. (отв. ред.), Болтушкина В. В., Кузеева Р. Г. Уфа: Башкнижиздат, 1981. 608 с.

Каримов 2006 - Каримов К. К. Культура Башкортостана (1917-2000). Уфа: Гилем, 2006. $148 \mathrm{c}$.

Коган 1966 - Коган Л. Н. Художественный вкус. Опыт конкретно социологического исследования. М.: Мысль, 1966. 213 с.

Куватов $1969-$ Куватов С. С. Башкирия издает. Уфа: Башкнижиздат, 1969. 150 с.

Кузбеков 2006 - Кузбеков Ф. Т. Башкирская журналистика как явление этнической культуры. Уфа: Китап, 2006. 382 с.

Кузыев 1958 - Кузыев Р. У. Дүртенсе биш йыллык йылдарында Башкорт АCCР-ында культура төззөлөшө (1946-1950 йылдар) (= Культурное строительство в Башкирской АССР в годы четвертой пятилетки). Өфө: [б. и.], 1958. 20 с.

Миркин 2013 - Миркин В. В. К истории советской радиосвязи и радиовещания в 1945 1965 гг. // Вестник Томского государственного университета. История. 2013. № 1 (21). C. 200-207.

Нуриев 1964 - Нуриев 3. Н. Общие заботы коммунистов города и села // Коммунист. 1964. № 18. C. 2-33.

Писатель Расих Ханнанов 2006 - Писатель Расих Ханнанов: «Нам пришлось спасать национальные газеты» [электронный ресурс] // Интервью ИА Regions.ru. 18.10.2006. URL: http://regions.ru/news/2018696/ (дата обращения: 15.02.2018).

Сабирова 2017 - Сабирова 3. Р. Радио: техническая новинка на службе революции и стро-
(In Russ.)

Ramazanov G. Productive conversation. Sovetskaya Bashkiria. 1976, June 6. No. 132 (16419). P. 4. (In Bash.)

Utägänov M. Useful sector. Sovetskaya Bashkiria. 1978, November 3. No. 255 (17152). P. 4. (In Bash.)

ительстве нового государства // Событие и текст: встречи и размышления в библиотеке. Сб. науч. ст. Уфа: Нац. библиотека РБ, 2017. C. $71-78$.

Сабирова 2019 - Сабирова 3. Р. Телевидение и башкирская наука во второй половине XX века: рука об руку // Урал-Алтай: через века в будущее. Матер. VIII Всеросс. тюркол. конф. (с междунар. участием). Уфа: ИИЯЛ УФИЦ РАН, 2019. С. 341-344.

Симонов $2013-$ - Симонов Н. С. Несостоявшаяся информационная революция: условия и тенденции развития в СССР радиоэлектронной промышленности и средств массовой коммуникации. М.: Университет Дмитрия Пожарского, 2013. 276 с.

Тимербулатов 2010 - Тимербулатов 3. М. Информационное пространство Башкортостана: состояние и перспективы // Инф.-аналит. мат-лы, посв. Третьему Всемирному курултаю башкир. Инф. бюллетень. № 2 (61). Уфа: Мир печати, 2010. С. 57-62.

Утешев 1962 - Утешев А. Живое слово сельского радио. Уфа: Башкнижиздат, 1962.74 с.

Янгиров 1972 - Янгиров Р. М. Некоторые вопросы развития культуры Советской Башкирии в годы семилетки (1959-1965) // Общее и национально-особенное в строительстве социализма и коммунизма. Уфа: БашГУ, 1972. C. 151-181.

Янгиров 2001 - Янгиров Р., Янгиров Р. Кино в Башкортостане. Уфа: [б. и.], 2001. 88 с.

Oukaderova 2017 — Lida Oukaderova. The Cinema of The Soviet Thaw. Space, Materiality, Movement. Bloomington: Indiana University Press, 2017. $267 \mathrm{p}$.

Riasanovsky 2000 - Riasanovsky Nicholas V. A History of Russia. $6^{\text {th }}$ ed. Bloomington: Indiana University Press, 2000. 374 p.

The Socialist Sixties 2013 - The Socialist Sixties. Crossing Borders in The Second World. Edited by Anne E. Gorsuch and Diane P. Koenker. Bloomington: Indiana University Press, 2013. $338 \mathrm{p}$.

Wolfe 2005 - Thomas C. Wolfe. Governing Soviet Journalism. The Press and The Socialist Person after Stalin. Bloomington: Indiana University Press, 2005. $240 \mathrm{p}$. 
Zerneva 2001 - Zerneva O. Soviet Studies: Culture // International Encyclopedia of The Social and

\section{References}

Akhunzyanov T. I. Ideological and Political Orientation of Print Media. Moscow: Politizdat, 1976. 62 p. (In Russ.)

Akhunzyanov T. I. Print Media of Soviet Bashkiria. Vol. 2. Ufa: Bashkir Book Publ., 1970. 364 p. (In Russ.)

Buravtsov V. History of communication means in Ufa. Bel'skie prostory. 2006, April. No. 4 (209). Pp. 130-133. (In Russ.)

Ganeev R. G. et al. (eds.) History of Ufa: A Brief Essay. Ufa: Bashkir Book Publ., 1981. 608 p. (In Russ.)

Gorsuch A. E., Koenker D. P. (eds.) The Socialist Sixties. Crossing Borders in The Second World. Bloomington: Indiana University Press, 2013. 338 p. (In Eng.)

Karimov K. K. Culture of Bashkortostan: 19172000. Ufa: Gilem, 2006. 148 p. (In Russ.)

Kogan L. N. Artistic Taste: A Sociological Survey. Moscow: Mysl, 1966. 213 p. (In Russ.)

Kuvatov S. S. Published in Bashkiria. Ufa: Bashkir Book Publ., 1969. 150 p. (In Russ.)

Kuzbekov F. T. Bashkir Print Media as a Phenomenon of Ethnic Culture. Ufa: Kitap, 2006. 382 p. (In Russ.)

Kuzyev R. U. Culture Building in the Bashkir ASSR during the $4^{\text {th }}$ Five-Year Plan: 1946-1950. Ufa, 1958. 20 p. (In Bash.)

Mirkin V. V. On the history of the Soviet radio in 1945-1965. Tomsk State University Journal of History. 2013. No. 1 (21). Pp. 200-207. (In Russ.)

Nuriev Z. N. Urban and rural Communists: common concerns. Kommunist. 1964. No. 18. Pp. 2-33. (In Russ.)

Oukaderova L. The Cinema of The Soviet Thaw. Space, Materiality, Movement. Bloomington: Indiana University Press, 2017. 267 p. (In Eng.)

Riasanovsky N. V. A History of Russia. $6^{\text {th }}$ ed. Bloomington: Indiana University Press, 2000. 374 p. (In Eng.)

Sabirova Z. R. Radio: technical innovation in the service of the Revolution and construction of the new state. In: Bikbulatova A. R. (comp.),
Behavioral Sciences. Second Edition. James Wright (ed.). 2015. Pp. 14710-14715.

Muratova A. D., Fatkhutdinova A. M. et al. (eds.) Event and Text: Meetings and Thoughts in the Library. Collected Scholarly Papers. Ufa: National Library of Bashkortostan, 2017. Pp. 71-78. (In Russ.)

Sabirova Z. R. Television and Bashkir science in the mid-to-late $20^{\text {th }}$ century: hand in hand. In: Ural-Altai: across Centuries into the Future. Conference Proceedings. Ufa: Institute of History, Language and Literature, 2019. Pp. 341-344. (In Russ.)

Simonov N. S. The Failed Information Revolution: Conditions and Trends for the Development of Radioelectronics and Communication Means in the USSR. Moscow: Dmitry Pozharsky University, 2013. 276 p. (In Russ.)

Timerbulatov Z. M. Information space of Bashkortostan: current conditions and prospects. In: The $3^{\text {rd }}$ World Qoroltai of Bashkirs. Newsletter No. 2 (61). Ufa: Mir Pechati, 2010. Pp. 57-62. (In Russ.)

Uteshev A. Living Word of Rural Radio. Ufa: Bashkir Book Publ., 1962. 74 p. (In Russ.)

Wolfe T. C. Governing Soviet Journalism. The Press and The Socialist Person after Stalin. Bloomington: Indiana University Press, 2005. 240 p. (In Eng.)

Writer Rasikh Khannanov: 'We had to save minority ethnic newspapers'. On: REGIONS.RU News Agency. Interview. Posted on October 18, 2006. Available at: http://regions.ru/news/2018696/ (accessed: February 15, 2018). (In Russ.)

Yangirov R. M. Soviet Bashkiria during the SevenYear Plan of 1959-1965: revisiting some issues of culture development. In: Nikiforov Yu. N. (ed.) Common and Ethnic-Specific Aspects of Socialist and Communist Construction. Ufa: Bashkir State University, 1972. Pp. 151-181. (In Russ.)

Yangirov R., Yangirov R. Cinema in Bashkortostan. Ufa, 2001. 88 p. (In Russ.)

Zerneva O. Soviet studies: culture. In: Wright J. (ed.) International Encyclopedia of The Social and Behavioral Sciences. $2^{\text {nd }}$ ed. 2015. Pp. 14710-14715. (In Eng.) 